\title{
Positive Correlation between Systematic and Idiosyncratic Volatilities in Korean Stock Return*
}

\author{
KYU-HO BAE ${ }^{* *}$ \\ Seoul National University \\ Seoul, Korea \\ JUNG-WOOK KIM ${ }^{* * *}$ \\ Seoul National University \\ Seoul, Korea
}

\begin{abstract}
Bartram, Brown, and Stulz (2016) report a strong positive correlation between systematic and idiosyncratic stock return volatilities and suggest heterogeneous firm-level responses to market wide shock may be an underlying driver. We test the hypothesis using Korean stock market data by including additional factors that reflect the macroeconomic conditions to the single factor model used in Bartram, Brown, and Stulz. Even though the correlation decreases by about $25 \%$ from 0.85 to 0.64 with additional factors, a substantial positive correlation still remains. In addition, we cannot find evidence that a high correlation industry experiences more volatile corporate sector dynamics in terms of changes in firm ranking and market share.
\end{abstract}

Keywords: systematic volatility, idiosyncratic volatility

* This research is supported by the Ministry of Education of the Republic of Korea and the National Research Foundation of Korea (NRF-2016S1A3A2923769). Jung-Wook Kim also acknowledges the financial support from the Institute of Management Research at Seoul National University.

** Graduate School of Business, Seoul National University, Seoul, Korea, 08826. Phone:+82-10-3930-0801, e-mail: bgh0801@snu.ac.kr.

*** Graduate School of Business, Seoul National University, Seoul, Korea, 08826. Phone: +82-2-880-6986, e-mail: jwkim87@snu.ac.kr. 


\section{INTRODUCTION}

Linear asset pricing models, such as the CAPM or factor models, decompose stock return into systematic and idiosyncratic components. In these models, systematic return and idiosyncratic return should be uncorrelated. However, this does not necessarily imply that the systematic volatility (SV) and idiosyncratic volatility (IV) should be uncorrelated as well. A recent paper by Bartram, Brown, and Stulz (2016) reports that these two volatility measures constructed using the firm level U.S. stock return data are robustly positively correlated.

This paper analyzes whether the finding of Bartram, Brown, and Stulz (2016) is present in the Korean stock return data and examine a plausible hypothesis not analyzed in the paper to explain the positive relationship.

Bartram, Brown, and Stulz (2016) examine whether certain firm characteristics, such as the illiquidity and the cost of arbitrage of a stock, may explain the magnitude of the correlation. They conjecture that the correlation may be higher for more illiquid stocks or stocks with higher arbitrage cost, since market wide information is incorporated only with a lag for these stocks. In this case, a stock price change due to the previous market wide shock could be misinterpreted as the idiosyncratic stock price change if there is no correlation between the previous and contemporaneous market wide shocks. They also examine whether the uncertainty regarding fundamentals might explain the pattern. For example, if a market wide shock is not properly represented by the included factors in regression models, heterogeneous reactions of firms to the shock may be misinterpreted as idiosyncratic price changes. This may create a positive correlation between SV and IV. In this case, firms with more growth options (e.g., high R\&D firms) may hedge the market wide risk better and, as a result, have lower correlation between SV and IV.

However, panel regression results of Bartram, Brown, and Stulz (2016) show mixed results for their conjecture. First two hypotheses on illiquidity and arbitrage cost were not supported consistently in the data. For example, regression coefficients have opposite signs in some specifications, contrary to their conjecture. Variables associated with the third hypothesis (market wide uncertainty) fared better. Regression coefficients have consistent signs across different 
specifications even though the economic significance is not large. They also find that market risk and firm specific earnings volatility is positively correlated, consistent with their hypothesis. With these results, Bartram, Brown and Stulz (2016) suggest that fundamental uncertainty and heterogeneous reactions among firms as the most promising future research area to identify the source of the positive correlation between SV and IV.

Their conclusion suggests that the source of the positive SV-IV correlation is not a mere stock market phenomenon, but may reflect underlying dynamics of fundamentals. This is consistent with the findings of Jovanovich and Rousseau (2001), Chun, Kim, Morck, and Yeung (2008), Chun, Kim and Morck (2011), Fink, Fink, Grullon, and Weston (2009), Chun, Kim, and Lee (2015), and Chun, Kim, and Morck (2016). They show that stock return volatility closely follows the volatility of fundamental variables and reflects the change in the composition of firms due to technology shocks. Specifically, Chun, Kim, and Lee (2015) and Chun, Kim, and Morck (2016) show that market wide productivity shocks, which initially increase SV, distinguish successful firms from unsuccessful ones. This increases the heterogeneity among firms, which results in high IV.

This paper investigates the market wide uncertainty hypothesis with a different approach not analyzed in Bartram, Brown, and Stulz (2016). In estimating SV and IV, Bartram, Brown, and Stulz (2016) use a single factor model with the CRSP value weighted index return as the factor. However, if other market wide factors affect stock returns, the single factor model is misspecified and IV contains the systematic volatility component as well. This may create a spurious positive correlation between SV and IV. We examine how much reduction is possible in the magnitude of the correlation between SV and IV by including various macroeconomic factors to the single factor model. We use Korean data between 2001 and 2016. Korea is a small open economy for which macro factors may play an important role in explaining stock return volatility.

We start with the single factor model and obtain the correlation of 0.846 between SV and IV. Next, we calculate the SV-IV correlation using Fama-French's 3 factor model. Bartram, Brown, and Stulz (2016) argue that firm size and book to market ratio may proxy for the growth options a firm has. Thus, including size and book to market factors to the single factor model may capture the additional systematic variation in return that the single factor model cannot. 
However, the correlation is reduced only by 0.055 in the 3 factor model specification. We add other factors to these base line models such as term premium, default premium, percentage changes in trade deficit, exchange rate, West Text Intermediate Price, and Industrial productions. The minimum correlation we obtained from these exercises is 0.636 , leaving substantial positive correlation unexplained. The relationship is very robust and observed in various sub sample periods as well.

We also find that there is a substantial cross-industry variation in the SV-IV correlation. This leads to a testable hypothesis. If a market wide shock induces more heterogeneous reactions of individual firms in certain industries, the ranking (based on market capitalization) or the market share of a firm in those industries may change much more. Thus, we check whether industries with higher correlations between SV and IV are industries where the volatility of annual firm ranking change or that of market share change is higher. However, we cannot find evidence supporting this conjecture.

The paper proceeds as follows. Section 2 discusses the data and variables. Section 3 report estimation results. Section 4 concludes.

\section{DATA AND VARIABLE CONSTRUCTION}

We use monthly stock return data for all the firms listed in the KOSPI market between January 2001 and December 2016. Firm characteristic variables such as book value and market capitalization are obtained from the FN Data Guide. Firms whose stock prices are less than 1,000 won or firms whose returns are exceeding daily price change limit are removed. Industry classification is from the Korea Exchange (KRX.)

Risk free rate ( $\mathrm{Rf}$ ) is monthly monetary stabilization bond rate. Excess market return (ERM) is defined as the value weighted average return minus risk free rate. Term spread (TS) is the yield difference between 10 year and 3 year government bond. Default premium (DR) is defined as the yield difference between 3 year government bond and BBB- corporate bonds. Risk free rate (Rf), Trade deficit (TD), Exchange rate (EX), West Texas Intermediate (WTI), Industrial production (IP) and Consumer Price Index (CPI) are monthly percentage changes acquired from the Economic Statistics 
System by Bank of Korea. ${ }^{11}$

\section{ESTIMATION RESULTS}

\section{Whole sample Results}

Panels A and B of Table 1 show the summary statistics of variables and correlations among them. While the correlation between DR and TS (two bond related variables) is relatively high at 0.337 , correlations among other variables are low on average and some are close to zero. Thus, many of the factors measure unrelated market wide shocks. ${ }^{2)}$

To estimate the annual time series of IV and SV, we estimate the following regressions for each stock each year using monthly data." Model 1 is the single factor model (excess market return) and models 2 through 4 are multifactor models where we add macro factors. Model 5 is the Fama-French's 3 factor model. Models 6 through 8 add the same set of macro factors as in models 2 through $4 .^{4)}$

Model 1: $R_{i t}=\beta_{0, i}+\beta_{1, i} R_{m t}+\varepsilon_{i t}$

Model 2: $R_{i t}=\beta_{0, i}+\beta_{1, i} R_{m t}+\beta_{2, i} T S_{t}+\beta_{3, i} D R_{t}+\varepsilon_{i t}$

Model 3: $R_{i t}=\beta_{0, i}+\beta_{1, i} R_{m t}+\beta_{2, i} C P I_{t}+\beta_{3, i} E X_{t}+\beta_{4, i} W T I_{t}+\beta_{5, i} I P_{t}+$ $\beta_{6, i} T D_{t}+\varepsilon_{i t}$

Model 4: $R_{i t}=\beta_{0, i}+\beta_{1, i} R_{m t}+\beta_{2, i} T S_{t}+\beta_{3, i} D R_{t}+\beta_{4, i} T D_{t}+\varepsilon_{i t}$

For stock $i, I V_{i, T}$ is defined as the standard deviation of $\varepsilon_{i t}$ obtained from monthly data for year T. $S V_{i, T}$ is defined as the difference between the standard deviation of $R_{i t}$ for year $T$ and $I V_{i, T}$. We

1) All the macro factors are calculated as the percentage monthly growth rate. Yoon (2010) shows that different ways of constructing macro factors either as the percentage growth rate or as the unexpected shock obtained from AR (1) model do not affect results much, which is true in our analyses as well .

2) TD exhibits extreme numbers in Panel A. This is due to the fact that when trade deficit changes its sign between two adjacent months (13 out of 204 months in our data), growth rate is not well defined. Our results remain qualitatively similar regardless of whether we include or exclude these 13 months.

3) We only include stocks with 10 or more monthly returns per year.

4) Kim, Kim, and Shin (2012) shows that the Model 6, which consists of FamaFrench's 3 factors, term spread and default premium, performs best in Korea based on both time-series test and cross sectional tests. 


\section{Table 1. Summary Statistics}

Excess market return (ERM) is the monthly value weighted return minus risk free rate. SMB and HML are size and book to market factors for the KOSPI market constructed as defined in Fama and French (1993). Term spread (TS) is the yield difference between 10 year and 3 year government bonds. Default premium (DR) is the yield difference between BBB- corporate bonds and 3 year government bond. Trade deficit (TD), Exchange rate (EX), West Texas Intermediate (WTI), Industry production (IP) are monthly percentage changes obtained from the Economic Statistics System by Bank of Korea.

Panel A: Summary Statistics

\begin{tabular}{c|c|c|c|c|c|c|c|c|c|c}
\hline \hline & ERM & SMB & HML & TS & DR & CPI & TD & EX & WTI & IP \\
\hline Mean & 0.017 & 0.011 & 0.009 & 0.928 & 5.487 & 0.002 & 0.134 & 0 & 0.007 & 0.003 \\
\hline Std & 0.06 & 0.046 & 0.047 & 0.798 & 1.349 & 0.004 & 20.556 & 0.025 & 0.087 & 0.013 \\
\hline MAX & 0.232 & 0.269 & 0.127 & 2.96 & 8.62 & 0.012 & 215.725 & 0.167 & 0.239 & 0.048 \\
\hline Q3 & 0.054 & 0.03 & 0.042 & 1.373 & 6.481 & 0.005 & 0.324 & 0.012 & 0.065 & 0.012 \\
\hline Median & 0.015 & 0.009 & 0.007 & 0.72 & 5.96 & 0.002 & -0.1 & -0.001 & 0.014 & 0.002 \\
\hline Q1 & -0.018 & -0.019 & -0.019 & 0.249 & 4.393 & 0 & -0.457 & -0.014 & -0.043 & -0.006 \\
\hline Min & -0.181 & -0.097 & -0.108 & -0.5 & 3.1 & -0.006 & -180.289 & -0.081 & -0.283 & -0.045 \\
\hline
\end{tabular}

Panel B: Correlations

\begin{tabular}{c|c|c|c|c|c|c|c|c|c|c}
\hline \hline & ERM & SMB & HML & TS & DR & CPI & TD & EX & WTI & IP \\
\hline ERM & 1 & 0.054 & -0.132 & 0.163 & 0.018 & 0.002 & -0.152 & -0.241 & 0.169 & 0.178 \\
\hline SMB & 0.054 & 1 & -0.305 & 0.036 & 0.163 & 0.117 & 0.056 & -0.099 & 0.089 & 0.075 \\
\hline HML & -0.132 & -0.305 & 1 & -0.062 & -0.135 & -0.02 & 0.046 & 0.006 & -0.017 & 0.05 \\
\hline TS & 0.163 & 0.036 & -0.062 & 1 & 0.337 & 0.093 & -0.042 & -0.204 & 0.162 & 0.152 \\
\hline DR & 0.018 & 0.163 & -0.135 & 0.337 & 1 & -0.092 & 0.046 & -0.019 & -0.087 & -0.02 \\
\hline CPI & 0.002 & 0.117 & -0.02 & 0.093 & -0.092 & 1 & 0.068 & 0.037 & 0.217 & 0.028 \\
\hline TD & -0.152 & 0.056 & 0.046 & -0.042 & 0.046 & 0.068 & 1 & 0.061 & -0.075 & -0.014 \\
\hline EX & -0.241 & -0.099 & 0.006 & -0.204 & -0.019 & 0.037 & 0.061 & 1 & -0.315 & -0.005 \\
\hline WTI & 0.169 & 0.089 & -0.017 & 0.162 & -0.087 & 0.217 & -0.075 & -0.315 & 1 & 0.136 \\
\hline IP & 0.178 & 0.075 & 0.05 & 0.152 & -0.02 & 0.028 & -0.014 & -0.005 & 0.136 & 1 \\
\hline
\end{tabular}

calculate the value weighted average of $I V_{i, T}$ and $S V_{i, T}$ for year $T$ to have the annual time series of IV and SV.

Table 2 reports the correlation between IV and SV obtained for 8 specifications. The correlation between IV and SV of model1 is very 


\section{Table 2. Correlation Between SV and IV}

Table 2 reports correlations between the systematic volatilities (SV) and the idiosyncratic volatilities (IV) obtained from various models. Model 1 is the market factor (ERM) model. Models 2 through 4 are multifactor models with macro factors. Model 5 is the Fama-French's 3 factor model. Models 6 through 8 have the same macro factors of models 2 through 4 in addition to the FamaFrench's 3 factors.

\begin{tabular}{l|c|c|c|c|c|c|c|c}
\hline IV & $\begin{array}{c}\text { Model } \\
1\end{array}$ & $\begin{array}{c}\text { Model } \\
2\end{array}$ & $\begin{array}{c}\text { Model } \\
3\end{array}$ & $\begin{array}{c}\text { Model } \\
4\end{array}$ & $\begin{array}{c}\text { Model } \\
5\end{array}$ & $\begin{array}{c}\text { Model } \\
6\end{array}$ & $\begin{array}{c}\text { Model } \\
7\end{array}$ & $\begin{array}{c}\text { Model } \\
8\end{array}$ \\
\hline Model 1 & 0.846 & 0.847 & 0.766 & 0.817 & 0.762 & 0.786 & 0.679 & 0.596 \\
\hline Model 2 & 0.887 & 0.871 & 0.816 & 0.845 & 0.811 & 0.809 & 0.713 & 0.627 \\
\hline Model 3 & 0.919 & 0.920 & 0.812 & 0.891 & 0.840 & 0.863 & 0.695 & 0.664 \\
\hline Model 4 & 0.900 & 0.889 & 0.820 & 0.856 & 0.818 & 0.824 & 0.713 & 0.627 \\
\hline Model 5 & 0.889 & 0.891 & 0.803 & 0.859 & 0.791 & 0.813 & 0.685 & 0.609 \\
\hline Model 6 & 0.917 & 0.906 & 0.844 & 0.879 & 0.832 & 0.833 & 0.721 & 0.642 \\
\hline Model 7 & 0.933 & 0.931 & 0.830 & 0.904 & 0.849 & 0.865 & 0.690 & 0.665 \\
\hline Model 8 & 0.922 & 0.916 & 0.839 & 0.884 & 0.833 & 0.841 & 0.712 & 0.636 \\
\hline
\end{tabular}

high at 0.846. Even though macro variables are added in Models 2 through 4 , the magnitudes of correlation do not change much, with the minimum correlation of 0.812 for model 3 . When we use the Fama-French's 3 factor model in Model 5, the correlation decreases somewhat to 0.791 . It decreases further with the addition of macro variables but the minimum correlation of 0.636 in model 8 is still very high. We repeat the exercise for various sub periods, but results remain robust. ${ }^{5)}$ Thus, contrary to our conjecture, the addition of macro factors does not affect the magnitude of correlation much.

\section{Industry Effects}

In this section, we examine whether positive correlation between IV and SV is concentrated in certain industries. For this purpose, we divide our sample into 16 industries and estimate model 1 through

5) Our sample period includes the 2008 global financial crisis, which may affect the correlation between SV and IV. We construct various sub periods by excluding 2008 or by excluding 2008 and adjacent years of 2007 and 2008 . We also divide our sample into two with roughly equal months. All the results remain qualitatively the same in all the sub samples. 


\section{Table 3. Industry Characteristics}

For each industry, we report the average of the number of firms and that of the weight of an industry based on the market capitalization measured at the end of each month. Std of ranking change is the volatility of the monthly change in the ranking of a firm based on the market capitalization for each industry. Std of weight change is the volatility of the change in the weight of a firm based on the market capitalization for each industry. Industry classification is as defined in the Korea Exchange (KRX.)

\begin{tabular}{|c|c|c|c|c|c|c|}
\hline Industry & $\begin{array}{l}\text { Number } \\
\text { of Firms }\end{array}$ & $\begin{array}{c}\text { Percentage } \\
\text { of Industry } \\
\text { Market } \\
\text { Share (\%) }\end{array}$ & $\begin{array}{l}\text { SV-IV } \\
\text { Corr of } \\
\text { Model1 }\end{array}$ & $\begin{array}{l}\text { SV-IV } \\
\text { Corr of } \\
\text { Model8 }\end{array}$ & $\begin{array}{c}\text { Std of } \\
\text { Ranking } \\
\text { Change } \\
(\%)\end{array}$ & $\begin{array}{c}\text { Std of } \\
\text { Weight } \\
\text { Change } \\
(\%)\end{array}$ \\
\hline Electricity \& Gas & 10.151 & 3.592 & 0.302 & -0.117 & 2.058 & 0.373 \\
\hline $\begin{array}{l}\text { Electrical \& } \\
\text { Electronic } \\
\text { equipment }\end{array}$ & 53.667 & 21.859 & 0.833 & 0.575 & 3.316 & 0.187 \\
\hline Food \& Beverage & 34.510 & 2.029 & 0.617 & 0.267 & 3.288 & 0.337 \\
\hline $\begin{array}{l}\text { Textile } \& \text { Wearing } \\
\text { apparel }\end{array}$ & 24.573 & 0.426 & 0.513 & 0.356 & 4.008 & 0.502 \\
\hline Distribution & 51.224 & 5.736 & 0.366 & 0.204 & 3.358 & 0.359 \\
\hline Construction & 34.615 & 2.8546 & 0.753 & 0.660 & 3.999 & 0.397 \\
\hline $\begin{array}{l}\text { Transport } \\
\text { equipment }\end{array}$ & 42.411 & 10.7925 & 0.908 & 0.839 & 3.058 & 0.302 \\
\hline Paper \& Wood & 19.979 & 0.217 & 0.505 & 0.356 & 5.994 & 0.571 \\
\hline $\begin{array}{l}\text { Non-metallic } \\
\text { mineral products }\end{array}$ & 20.552 & 0.4964 & 0.411 & 0.291 & 3.812 & 0.587 \\
\hline Services & 90.792 & 11.707 & 0.641 & 0.634 & 2.689 & 0.211 \\
\hline $\begin{array}{l}\text { Iron \& Metal } \\
\text { products }\end{array}$ & 39.839 & 5.478 & 0.426 & 0.301 & 3.250 & 0.226 \\
\hline Chemicals & 79.953 & 8.425 & 0.874 & 0.843 & 2.543 & 0.197 \\
\hline Machinery & 33.839 & 1.598 & 0.783 & 0.763 & 4.287 & 0.470 \\
\hline $\begin{array}{l}\text { Transport \& } \\
\text { Storage }\end{array}$ & 18.839 & 1.901 & 0.586 & 0.485 & 3.181 & 0.722 \\
\hline Medical supplies & 35.630 & 1.202 & 0.231 & 0.220 & 4.321 & 0.354 \\
\hline $\begin{array}{l}\text { Other } \\
\text { manufacture }\end{array}$ & 9.740 & 1.2716 & 0.216 & 0.215 & 4.978 & 0.261 \\
\hline
\end{tabular}


model 8 for each industry. ${ }^{6)}$ Table 3 shows the number of stocks and the percentage of market share of each industry. For brevity, we only report the correlation obtained from model 1 and model 8 only. Correlation numbers exhibit a substantial variation across industries. Electricity and Gas, which represents about 3.6\% of the total market capitalization, has a correlation close to zero in model 8. Correlations vary widely across industries ranging from 0.204 of Distribution to 0.843 of Chemical.

The substantial cross sectional variation in the SV-IV correlation across industries provides us an opportunity to test the conjecture of Bartram, Brown, and Stulz (2016). They predict that higher systematic volatility may be associated with higher firm specific volatility since market wide uncertainty affects firms' decisions to invest heterogeneously. If this conjecture is correct, we expect industries with higher correlation between IV and SV are industries where the volatility of the change in the ranking or that of the change in the market share of a firm are higher. The former is defined as the standard deviation of the monthly change in the ranking of a firm based on the market capitalization for the industry. The latter is defined as the standard deviation of the monthly change in the weight of a firm based on the market capitalization for each industry. The last two columns of Table 3 show the magnitudes of these two variables for each industry. They are positively correlated with each other (0.361). However, the correlation between the volatility of the ranking (market share) change and the SV-IV correlation (model 8) is very small and has a negative rather than positive sign of $-0.077(-0.167)$.

Lastly, we add industry portfolio return in models 1 through 8 as an additional factor to check whether the inclusion of this factor affects the magnitude of SV-IV correlation. However, results remain qualitatively similar.

\section{CONCLUSION}

Bartram, Brown, and Stulz (2016) point out that the source of positive correlation is most likely driven by fundamental risks.

6) We exclude industries with the average number of stocks equal or less than 5 per month. We also exclude the financial industry. 
This conjecture is consistent with papers that report stock return volatility may be associated with the changes in composition of firms due to market wide shocks (Jovanovich and Rousseau, 2001; Fink, Fink, Grullon, and Weston, 2009) or heterogeneous reaction of individual firm's stock return to market wide shocks (Chun, Kim, and Morck, 2011, 2016; Chun, Kim, and Lee, 2015). However, our analyses show that adding additional macro factors or industry factors to linear asset pricing models does not substantially reduce the magnitude of positive correlation.

Weak results of Bartram, Brown, and Stulz (2016) and ours in explaining possible causes of the positive correlation between SV and IV necessitate a formal structural model that links the two volatilities. Pastor and Veronesi (2009) analyze the time variation of the relative importance of the two volatilities in a general equilibrium model but no paper analyzes why there should be a strong comovement between them. This remains as a promising research area to answer the strong and robust patterns found in Bartram, Brown, and Stulz (2016) and this paper.

\section{REFERENCES}

Bartram, Söhnke M., Gregory W. Brown, and René M. Stulz, 2016, Why Does Idiosyncratic Risk Increase with Market Risk? NBER Working Paper No. w22492.

Chun, Hyunbae, Jung-Wook Kim, and Jason Lee, 2015, How Does Information Technolgy limprove Aggregate Productivity? A New Channel of Productivity Dispersion and Reallocation, Research Policy 44, 9991016.

Chun, Hyunbae, Jung-Wook Kim, Randall Morck, and Bernard Yeung, 2008, Creative destruction and firm-specific performance heterogeneity, Journal of Financial Economics 89, 109-135.

Chun, Hyunbae, Jung-Wook Kim, and Randall Morck, 2011, Varying Heterogeneity among U.S. Firms: Facts and Implications, Review of Econoimcs and Statistics 93, 1034-1052.

Chun, Hyunbae, Jung-Wook Kim, and Randall Morck, 2016, Productivity Growth and Stock Returns: Firm- and Aggregate-Level Analyses, Applied Economcis 48, 3644-3664.

ECOS (Economic Statistics System) by the Bank of Korea. https://ecos.bok. or.kr/EIndex_en.jsp

Fink, Jason, Kristin E. Fink, Gustavo Grullon, and James P. Weston, 2009, 
What Drove the Increase in Idiosyncratic Volatility During the Internet Boom?, Journal of Financial and Quantitative Analysis 45, 1253-1278.

Jovanovich, Boyan, and Peter L. Rousseau, 2001, Why Wait? A Century of Life Before IPO, American Economic Review 91, 336-341.

Kim, Soon-Ho, Dongcheol Kim, and Hyun-Soo Shin, 2012, Evaluating Asset Pricing Models in the Korean Stock Market, Pacific-Basin Finance Journal 20, 198-227.

Pastor, Lubos, and Pietro Veronesi, 2009, Technological Revolutions and Stock Prices, American Economic Review 91, 336-341.

Yoon, Sang-Young, 2010, The Effect of Macro Factors on the Cross Section of Stock Return, working paper, in Korean.

Received March 1, 2018

Revised June 12, 2018

Accepted June 14, 2018 
